\title{
TRANSPLANTE DE FÍGADO: INDICAÇÃO E SOBREVIDA ${ }^{1}$
}

\section{LIVER TRANSPLANTATION: INDICATION AND SURVIVAL}

\author{
Orlando de Castro-e-Silva Jr² \\ Ajith Kumar Sankarankutty ${ }^{3}$ \\ Gustavo Ribeiro de Oliveira ${ }^{4}$ \\ Eduardo Pacheco ${ }^{5}$ \\ Fernando Silva Ramalho ${ }^{6}$ \\ Karina Dal Sasso ${ }^{7}$ \\ Eduardo Tolentino ${ }^{4}$ \\ Enio David Mente ${ }^{4}$ \\ Alex Viana C. França ${ }^{8}$ \\ Ana L. C. Martinelli9
}

\section{RESUMO}

O sucesso dos transplantes de fígado certamente seria comprometido se a avaliação pré-operatória dos pacientes não fosse realizada de forma adequada. Isto se justifica devido ao reconhecimento de que o sucesso da cirurgia depende, em princípio, do diagnóstico da doença de base, da determinação de sua extensão e do grau de repercussão sistêmica. No final das décadas de setenta a noventa os progressos da hepatologia na identificação das hepatites virais e no manejo da ascite e da síndrome hepatorrenal melhoraram sobremaneira a expectativa de vida do doente portador de doença hepática crônica. Mas, sem dúvida o transplante ortotópico do fígado (TOF) foi o espetacular avanço da hepatologia moderna. Atualmente o transplante é um tratamento eficaz das hepatopatias crônicas, e o índice de sobrevivência global aos 3 anos é ao redor de $80 \%$. É, portanto, uma alternativa de tratamento indicada nos casos terminais, onde a mortalidade com tratamentos conservadores pode atingir até $70 \%$ ao final de 12 meses. Neste artigo, os autores comentam aspectos do TOF, relacionados à indicação e a sobrevida. Disponível em URL: http://www.scielo.br/acb
Descritores - Transplante de fígado; Doadores; Receptores; Hepatopatias crônicas.

\begin{abstract}
The success of liver transplantation would be certainly compromised if the pre-operative evaluation was not adequately performed. The success of the liver transplantation depends on the diagnosis of the underlying hepatic disease, the determination of its extension and the degree of systemic repercussion. In the last 30 years, the progress in hepatology, the identification of viral hepatitis and the better management of ascitis and hepatorenal syndrome have increased the life expectancy of patients with chronic liver failure. Undoubtedly, orthotopic liver transplantation represents a great advance in modern hepatology. Nowadays, liver transplantation represents a valid therapeutic option for chronic liver diseases with (and presents) a mean survival rate of about $80 \%$ in 3 years. Thus, it is an indicated treatment in situations where the conservative treatment (would) could lead to a (incur) mortality rate as high as $70 \%$ in one year. In this article the authors comment (on) various aspects of Orthotopic Liver
\end{abstract}

1 Trabalho realizado pelo Grupo Integrado de Transplante de Fígado do Hospital das Clínicas da FMRP - USP

2 Professor Associado do Departamento de Cirurgia da Faculdade de Medicina de Ribeirão Preto da Universidade de São Paulo

3 Professor Assistente - Docente FAEPA - do Departamento de Cirurgia e Anatomia da FMRP- USP

4 Pós Graduando e Médico Assistente do Departamento de Cirurgia e Anatomia da FMRP- USP

5 Pós Graduando do Departamento de Cirurgia e Anatomia da FMRP- USP

6 Professor Doutor do Departamento de Cirurgia e Anatomia da FMRP- USP

7 Enfermeira Chefe do Grupo Integrado de Transplante de fígado - FMRP - USP

8 Professor Doutor (Docente FAEPA ) do Departamento de Clinica Médica da FMRP-USP

9 Professor Doutor do Departamento de Clinica Médica da FMRP-USP 
Transplantation related to indications and survival rates.

Key words - Liver Transplantation: donors; receptors; chronics hepatopaties

\section{INTRODUÇÃO}

O sucesso das hepatectomias regradas e dos transplantes de fígado certamente seria comprometido se a avaliação pré-operatória dos pacientes não fosse realizada de forma adequada. Isto se justifica devido ao reconhecimento de que o sucesso da cirurgia depende, em princípio, do diagnóstico da doença de base, da determinação de sua extensão e do grau de repercussão sistêmica. A precisa localização anatômica com identificação de estruturas relacionadas e a estimativa do grau de acometimento da função hepática são essenciais. Seguramente, sem o conhecimento e apreciação desses dados básicos a relação entre o risco e benefício não poderia ser avaliada e os resultados da intervenção poderiam ser catastróficos.

Muito já foi escrito sobre o trauma e suas conseqüências funestas para o ser vivo. Da mesma forma, pode-se dizer que a intervenção cirúrgica consiste em submeter um indivíduo à situação semelhante ao trauma. A diferença fundamental é que o trauma cirúrgico, por planejado, restringe a lesão ao tratamento necessário do doente através da correção anatômica de estruturas ou remoções teciduais. Este tipo de intervenção conta, também, com o concurso do anestesiologista para prover o paciente de condições ideais e de hipnose, analgesia, relaxamento muscular e proteção neurovegetativa de perfusão e oxigenação dos tecidos, além de fornecer quantidade satisfatória de fluidos energéticos que atendam às demandas metabólicas.

Até há alguns anos, o tratamento das doenças hepáticas crônicas era desalentador. No final das décadas de setenta a noventa os progressos da hepatologia na identificação das hepatites virais, no manejo da ascite e da síndrome hepatorrenal melhoraram sobremaneira a expectativa de vida do doente portador de doença hepática crônica. Mas, sem dúvida o transplante ortotópico do fígado (TOF) foi o espetacular avanço da hepatologia moderna ${ }^{1}$.

A história dos transplantes de órgãos sólidos vasculares teve início com os trabalhos de Carrel e Ullmann em 19022,3. Welch, em 1955, descreveu o transplante de fígado heterotópico em cães, iniciando uma importante linha de pesquisa. Starzl et al. desempenharam um papel de pioneirismo e vanguarda na cirurgia do transplante hepático, a partir da estruturação do grupo de Chicago, em $1958^{4,5}$.
Desde os primeiros transplantes de fígado, realizados por Cannon em $1956^{6}$ e Starzl et al. em $1963^{5}$, assistiu-se a um progresso extraordinário nos resultados do procedimento devido ao aperfeiçoamento da técnica operatória, maior precisão das indicações e, principalmente, devido a uma melhor compreensão dos mecanismos imunológicos presentes no fenômeno da rejeição. No entanto, sem adequada terapia imunossupressora os resultados do procedimento eram desanimadores e apresentavam baixos índices de sobrevivência (20\% em dois anos).

O desenvolvimento de soluções de conservação de órgãos iniciou-se a partir da década de 60 , com os trabalhos pioneiros de Belzer em transplante renal ${ }^{7}$. Estas pesquisas abriram portas para o aperfeiçoamento de novas soluções de conservação (Collins) ${ }^{8}$ nas décadas seguintes, até que no final da década de 80 o grupo da Universidade de Wisconsin padronizou uma nova e revolucionária solução. Esta continha inibidores da tumefação celular, tampões eficientes e nutrientes que propiciaram um expressivo aumento no tempo de preservação do fígado ${ }^{9}$. Esta solução é conhecida como "Universidade de Wisconsin" e atualmente é a solução mais utilizada na conservação de fígados para transplante. O advento desta nova solução propiciou a realização do transplante de modo eletivo e possibilitou o transporte de órgãos a outros centros, viabilizando e melhorando a distribuição dos órgãos para os diversos centros transplantadores tornando possível a captação de órgãos a longa distância ${ }^{10}$.

A introdução da azatioprina na década de 70 foi um marco importante na história dos transplantes ${ }^{11,12,13}$, mas foi o uso da ciclosporina A como medicamento adicional no controle da rejeição no final da década de 70 , que possibilitou uma melhora progressiva na sobrevida de doentes submetidos ao transplante ${ }^{14}$. A partir da década de 80, novos grupos de expressão foram criados em toda a Europa Central e Ocidental, EUA, Argentina e Brasil. Atualmente se observa um grande esforço de implantação do TOF em países que enfrentam problemas éticos, culturais, religiosos e filosóficos no Oriente Médio, Europa Oriental e Japão. Alguns deles, como o Japão, iniciaram nos últimos cinco anos o programa de transplantes utilizando doadores vivos inter-relacionados (um parente co-sanguíneo cede o lobo hepático esquerdo para o receptor).

Em 1983, Starzl conseguiu demonstrar às autoridades americanas, durante uma conferência nacional, que o transplante apresentava resultados positivos e podia ser considerado como atitude terapêutica e não mais um procedimento experimental ${ }^{15}$. Nesta época haviam sido realizados cerca de 500 
transplantes. Dez anos depois, Paris foi a sede de nova conferência internacional, onde se constatou que 10 mil procedimentos já haviam sido realizados em todo o mundo ${ }^{16}$. Constatou-se também que aumentava a confiança e a procura ao procedimento e, em conseqüência, as filas de espera aumentavam e muitos doentes faleciam à espera de um órgão. Apareceram então novos problemas, como a escassez de doadores e a adequada seleção dos potenciais candidatos ao transplante.

Atualmente o transplante é um tratamento eficaz nas hepatopatias crônicas, e apresenta um índice de sobrevivência global aos 3 anos ao redor de $80 \%$. É, portanto, uma alternativa de tratamento indicado nos casos terminais, onde a mortalidade com tratamentos conservadores pode atingir até $70 \%$ ao final de 12 meses.

\section{Indicação (Tabelas 1 e 2)}

Para a eleição do momento mais adequado à realização do transplante é fundamental conhecer profundamente a história natural da doença e os fatores prognósticos envolvidos em cada caso. Além disso, é necessário que se identifiquem contra-indicações absolutas ou relativas ao procedimento, e a existência de fatos que sabidamente piorem o prognóstico a médio e longo prazo ${ }^{17,18}$.

Tabela 1 - Indicações de transplante hepático em adultos

A) Doenças Hepáticas Colestáticas Crônicas

a.1.) Cirrose biliar primária

a.2.) Cirrose biliar secundária

a.3.) Colangite esclerosante primária

B) Doenças Hepatocelulares Crônicas

b.1.) Cirrose hepática de etiologia viral

b.2.) Cirrose hepática autoimune

b.3.) Cirrose hepática por tóxicos ou chagas

b.4.) Cirrose alcoólica

b.5.) Cirrose criptogenética

C) Doenças Hepáticas Metabólicas

c.1.) Hemocromatose avançada, em fase cirrótica

c.2.) Doença de Wilson

c.3.) Deficiência de alfa-1-antitripsina, em fase cirrótica

D) Doenças Hepáticas Vasculares

d.1.) Síndrome de Budd-Chiari

d.2.) Doença hepática veno-oclusiva

E) Tumor Primário do Fígado

F) Trauma 
Tabela 2 - Parâmetros clínicos e bioquímicos para indicação de transplante hepático.

A) Insuficiência Hepática Aguda

a.1.) Bilirrubina total $>20 \mathrm{mg} / \mathrm{dl}$

a.2.) Tempo de protrombina $>50$ segundos ou RNI maior 3,5

a.3.) Encefalopatia hepática (grau 3)

B) Doença Hepática Crônica

b.1.) Doença Colestática

b.1.1.) Bilirrubina total $>12,5 \mathrm{mg} / \mathrm{dl}$

b.1.2.) Prurido intratável

b.1.3.) Doença óssea intratável

b.2.) Doença Hepatocelular

b.2.1.) Albumina sérica $<2,5 \mathrm{~g} / \mathrm{dl}$

b.2.2.) Encefalopatia hepática

b.2.3.) Tempo de protrombina $>5$ segundos acima do normal

b.3.) Parâmetros indicativos de transplante comuns a várias condições

b.3.1.) Síndrome hepatorrenal

b.3.2.) Peritonite bacteriana espontânea

b.3.3.) Ascite refratária a tratamento clínico

b.3.4.) Episódios recorrentes de sepse biliar

b.3.5.) Episódios repetidos de sangramento digestivo

b.3.6.) Carcinoma hepatocelular

A indicação do transplante hepático está reservada aos portadores de insuficiência hepática crônica terminal que têm expectativa de vida inferior a $20 \%$ ao final de 12 meses, se não forem transplantados ${ }^{19}$ e naqueles cuja progressão da doença hepática se não transplantados, resulte em mortalidade que exceda aquela decorrente do próprio transplante.

Basicamente a indicação do transplante hepático tem por objetivo prolongar a vida do paciente proporcionando satisfatória qualidade de vida e recuperação da capacidade de trabalho. Desde a introdução da ciclosporina nos anos 80 , resultados cada vez melhores vêm sendo observados de modo que a sobrevida dos pacientes transplantados é sensivelmente superior comparada a de outras formas de tratamento da insuficiência hepática.

Este fato tem permitido a indicação mais precoce do transplante hepático nos portadores de menor risco operatório ${ }^{20}$, expandindo assim as indicações deste tratamento. Considera-se que os candidatos à espera do transplante hepático atendam a 4 requisitos fundamentais:

a) Estabelecimento de diagnóstico específico da doença

b) Demonstração inequívoca da gravidade da doença mediante provas documentadas

c) Identificação de possível complicação que poderá prejudicar a sobrevida do paciente

d) Estimativa da sobrevida do paciente submetido ou não ao transplante.

Uma vez identificado o paciente como candidato potencial ao transplante, parâmetros clínicos e bioquímicos devem ser pesquisados a fim de que as funções de excreção e síntese, as alterações metabólicas e os distúrbios psicossociais possam ser avaliados 
para justificar o momento da realização do procedimento. Por outro lado, contra indicações ao transplante hepático de ordem absoluta e relativa estão bem definidas (tabela 3). Neste aspecto convém salientar que com o aumento da experiência clínica, as contra-indicações de ordem absoluta vem diminuindo, enquanto que as contra-indicações de ordem relativa vem aumentando ${ }^{19}$. Assim, por exemplo, a idade acima de 60 anos, o alcoolismo crônico, e a doença renal crônica podem não contra-indicar o transplante se cuidados especiais forem adotados.

Quanto ao futuro do candidato potencial ao transplante, deve-se questionar a realização de cirurgias prévias ao transplante tais como derivações venosas no tratamento da hipertensão portal ou derivações bíleodigestivas para controlar problemas biliares, uma vez que estes procedimentos dificultam tecnicamente a execução do transplante, pela formação de aderências e neoformações vasculares ${ }^{8}$.

Tabela 3 - Contraindicações ao transplante hepático.

A) Contraindicações Absolutas

a.1.) Metástase hepatobiliar ou em outros órgãos

a.2.) Doença cardiopulmonar avançada

a.3.) Infecção ativa extra-hepática

B) Contraindicações Relativas

b.1.) Etilismo ativo

b.2.) Uso abusivo de drogas

b.3.) Sorologia positiva para HIV

b.4.) Positividade para replicação do vírus da hepatite B

b.5.) Doença renal crônica avançada

\section{SELEÇÃO DOS PACIENTES}

Na seleção do paciente para a realização do transplante hepático é fundamental escolher dentre os portadores de insuficiência hepática terminal aqueles que, embora preenchendo as condições para o transplante, não sejam portadores de outras doenças concomitantes que implique em curta expectativa de vida. É fundamental que o candidato tenha ciência não somente dos riscos do procedimento operatório em si, bem como, aceite correr estes riscos. É importante também a avaliação de fatores extrahepáticos que possam aumentar os riscos do transplante ou reduzir a probabilidade de sobrevida. Algumas condições clínicas não usuais precisam ser lembradas, tais como: síndrome hepatopulmonar, colecistite recorrente em cirrose hepática descompensada, dentre outras. Em algumas ocasiões, embora estejam presentes condições clínicas e laboratoriais que recomendam o transplante, o paciente pode estar totalmente assintomático e incapacitado de assumir os riscos do transplante dada a falta de evidência subjetiva da enfermidade. Por outro lado é recomendável o transplante nos casos em que embora a expectativa de vida seja favorável, a presença de sintomas decorrentes da doença hepática agravam de tal modo a qualidade de vida que o paciente se encontra mais sensível a aceitar os riscos do procedimento.
Também, tem sido verificado que a recuperação da capacidade de trabalho e a volta às atividades sociais após o transplante são mais fáceis quando não ocorre período de incapacitação antes da cirurgia ${ }^{2}$. Assim, do ponto de vista sócio-econômico é melhor recomendar o transplante mais cedo para o paciente com doença hepática progressiva.

Na seleção do paciente ao transplante hepático a avaliação cardiocirculatória é fundamental, uma vez que, durante $\mathrm{o}$ ato operatório haverá alterações hemodinâmicas e do débito cardíaco. A presença de cardiopatia ou mesmo de cirurgia coronária prévia, necessariamente não contra indica o transplante, se o enfermo apresentar razoável expectativa de vida. A melhor previsão de tolerância cardíaca frente às alterações hemodinâmicas inerentes a cirurgia do transplante é obtida por meio da história clínica e do exame físico associado a angiografia e ecocardiograma. A doença coronariana deve ser igualmente afastada sobretudo nos hipertensos, nos portadores de valvuloplastias, nos fumantes, nos obesos, nos cirróticos com colestase e hiperlipidemia e principalmente nos cirróticos com restrição da deambulação que podem apresentar a enfermidade sub-clínica.

A hipertensão pulmonar que pode estar associada à hipertensão portal deve ser diagnosticada no pré-operatório, uma vez que, embora não contra-indique o 
transplante implica em necessidade de tratamento clínico complementar pois é causa de aumento da mortalidade $^{22}$.

A evidência de capacidade pulmonar restritiva ou obstrutiva que não possa ser explicada pela elevação diafragmática devida a ascite, é contra indicação ao transplante, sobretudo nos mais velhos. A síndrome hepatopulmonar pode ser reversível com o transplante hepático embora seja responsabilizada por maior morbidade ${ }^{23,24}$.

A presença de diabetes melitus raramente é contra indicação ao transplante hepático. É importante avaliar o prognóstico do diabetes que poderá contra indicar o transplante. Algumas condições que acompanham o diabetes devem ser avaliadas tais como, doença coronariana, nefropatia, neuropatia, retinopatia, arteriopatia e resistência a infecção.

A obesidade não aumenta a mortalidade peroperatória ${ }^{[10]}$ embora possa haver maior incidência de doença tromboembólica, deiscência de parede e menor expectativa de vida, aliás, como acontece em outros tipos de cirurgia geral.

A desnutrição é fator de risco ao transplante [25] embora se constitua em indicação do mesmo. A melhora do estado nutricional deve ser objetivo a ser perseguido pela equipe transplantadora, mas não a ponto de postergar a cirurgia na expectativa de diminuir os riscos operatórios.

A idade avançada, isto é, pacientes acima de 65 anos apresentam risco operatório maior e recuperação pós-operatória mais lenta, conceito este que parece ser devido a presença de outras doenças não reconhecidas. Assim, na ausência de outras afecções a indicação de transplante pode constituir-se em problema ético. Vale salientar que resultados recentes têm recomendado a sua prática em doentes com idade superior a 65 anos com sobrevida de $80 \%$ no $1^{\circ}$ ano e $75 \%$ no $3^{\circ}$ $\mathrm{ano}^{9,26}$. É de fundamental importância que o paciente idoso seja transplantado antes que se estabeleçam as manifestações terminais da cirrose tais como insuficiência renal, encefalopatia grave e principalmente caquexia hepática.

A sobrevida anual superior a $75 \%$ sugere que atualmente é mais fácil pesquisar os fatores responsáveis pela mortalidade do que os previsíveis de sobrevida ${ }^{20}$.

Independentemente da qualificação e da experiência do grupo transplantador, a gravidade do estado clínico do receptor por ocasião do transplante é fator que influi tanto na morbidade quanto na mortalidade peroperatória. Da mesma forma a natureza da hepatopatia empobrece os resultados do transplante como acontece na hepatite pelo vírus $B$, nas doenças malignas e na insuficiência hepática fulminante de qualquer etiologia.
Por outro lado, os resultados do transplante observados em portadores de doenças colestáticas indicam melhor sobrevida ${ }^{28}$. Igualmente, os pacientes alcoólatras selecionados apresentam bons resultados de sobrevida não obstante a complexidade da doença ${ }^{27,28}$.

Doenças que atingem os grupos etários mais avançados (cardiorespiratórias, renais e neurológicas) contribuem para reduzir a sobrevida.

Fatores diretamente relacionados ao doador tais como idade, alterações hemodinâmicas, tempo de isquemia fria do enxerto, infiltração gordurosa do fígado e doadores marginais também podem empobrecer o prognóstico quanto à sobrevida.

Os efeitos colaterais das drogas imunossupressoras e as complicações hepatobiliares podem prejudicar a qualidade de vida dos transplantados.

A experiência tem recomendado nos cirróticos, cuidadosa avaliação cardiológica pré-operatória que inclui medida do débito cardíaco, cálculo do shunt pulmonar e da resistência vascular sistêmica. Assim valores elevados de shunt pulmonar com resistência vascular sistêmica baixa constituem fatores de risco ao transplante $^{29}$. O débito cardíaco baixo que não responde a sobrecarga de volume e a hipoxemia $(\mathrm{PO} 2<50 \mathrm{mmHg})$ constituem contra-indicação à cirurgia ${ }^{29}$.

A avaliação pré-operatória da perveabilidade da veia porta através da ecodopplerfluxometria abdominal informa sobre a presença de trombose portal que não é contra-indicação absoluta ao transplante pode ser causa de sangramento per-operatório ${ }^{30}$.

Convém lembrar que aspectos ético-morais, além da avaliação clínica, são parâmetros fundamentais na seleção do receptor. A equipe transplantadora, muitas vezes, luta para não excluir o receptor de alto risco. Todavia a presença concomitante da insuficiência renal, sepsis e coma profundo que não respondem clinicamente aos cuidados dos intensivistas limitam sobremaneira o sucesso da cirurgia.

A sobrevida atual vem progressivamente aumentando, alcançando 60 - 70\% em 5 anos, caracterizada pela boa qualidade de vida que oferece aos pacientes ${ }^{31}$ com completa reabilitação psicossócio-econômica.

O principal fator que influencia a sobrevida do transplante é o carácter eletivo ou de urgência da operação. Certamente a escolha do paciente a ser transplantado e a experiência da equipe cirúrgica influenciam no resultado. A avaliação pré-operatória das funções fisiológicas do receptor constitui fator preponderante quanto à sobrevida do paciente. A gravidade das condições clínicas do pré-operatório (classificação Child-Pugh tipo ' $C$ ') apresenta enorme relação com a insuficiência múltipla de órgãos no pós-operatório. Deste modo é 
discutível identificar os candidatos a transplante que apresentem melhor reserva fisiológica, aos quais se da prioridade na alocação de órgãos, com o propósito de melhorar a sobrevida. Todavia, doentes graves com reserva fisiológica comprometida, também devem ser encaminhados ao transplante como tentativa válida de tratamento que é, sem sombra de dúvidas, superior a outras modalidades de terapêutica ${ }^{12}$.

\section{DOENÇAS HEPÁTICAS COM INDICAÇÕES MAIS FREQUENTES}

\section{1) Cirrose Biliar Primária}

A cirrose biliar primária acomete principalmente mulheres com idade ao redor de 40 anos.

A questão nesta doença se resume na identificação de fatores que possam complicar o quadro clínico, agravando o prognóstico. A cirrose biliar primária é considerada doença de bom prognóstico para o transplante oferecendo sobrevida de $70 \%$ aos 5 anos $^{32,33}$. A sobrevida em 5 anos em grandes séries de transplantados varia de $60 \%$ a $80 \%{ }^{[2,13,32]}$. As indicações para o transplante incluem qualquer das situações como icterícia progressiva (bilirrubina $>10 \mathrm{mg} / \mathrm{dl}$ ), varizes de esôfago sangrantes, ascite incontrolável, osteodistrofia progressiva, prurido intratável ou encefalopatia hepática. A recidiva da cirrose biliar no fígado transplantado ainda é objeto de investigações.

\section{2) Colangite Esclerosante Primária}

Os portadores desta afecção costumam ser bons candidatos ao transplante hepático; geralmente são adultos do sexo masculino com idade entre 20 e 40 anos, muitas vezes, portadores também de retocolite ulcerativa. As indicações clínicas são semelhantes às de cirrose biliar primária. Nos portadores de colangite esclerosante a presença do colangiocarcinoma e do carcinoma do intestino grosso deve ser investigada antes da realização da cirurgia. A sobrevida alcança $85 \%$ em 1 ano e $75 \%$ em 3 anos $^{35,36}$. A possível recidiva da doença no fígado transplantado é controvertida.

\section{3) Cirrose Hepática}

Geralmente estes pacientes são portadores de hepatopatia crônica de longa duração que determinam importantes alterações clínicas em todo o organismo. Em decorrência, a sobrevida é bem menor aos 5 anos, ou seja, em torno de $60 \%$. A cirrose hepática é a principal indicação do transplante hepático $(70 \%-90 \%$ das indicações) $)^{6}$. As indicações do transplante em pacientes portadores de cirrose são comuns a qualquer etiologia. Devem ser transplantados pacientes com ex- pectativa de vida inferior a 1 ano, devendo-se incluir no programa de transplante pacientes que reúnam algumas das indicações relacionadas na tabela 3 .

Ao lado do uso do álcool, os vírus das hepatites são a principal causa de cirrose. $\mathrm{O}$ vírus $\mathrm{B}$, acompanhado ou não do vírus Delta, e o vírus $\mathrm{C}$ determinam formas crônicas de hepatite cuja fase final é o estabelecimento da cirrose hepática em $20 \%$ - 50\% dos casos ${ }^{37,38}$. A recorrência da doença viral no fígado transplantado é também a regra, independentemente do emprego de terapêutica preventiva, nos casos em que a replicação do vírus $B$ está presente no pré-operatório ${ }^{39}$. A recorrência do vírus $\mathrm{B}$ costuma ser mais grave do que a recidiva do vírus $\mathrm{C}$, praticamente presente em $100 \%$ dos casos transplantados ${ }^{11}$. Protocolos para prevenção da hepatite B constam do emprego de imunoglobulina específica, interferon e principalmente de medicações antivirais como lamivudine e famciclovir ${ }^{17,40}$.

Os portadores de cirrose por hepatite autoimune apresentam melhor prognóstico para a cura com o transplante e a manutenção da corticoterapia após o transplante melhora a recidiva da doença autoimune hepática.

\section{4) Síndrome de Budd-Chiari}

Os pacientes portadores desta síndrome (trombose das veias hepáticas) podem necessitar do transplante se não for possível o controle da ascite ou ocorrer insuficiência hepática. Estes pacientes necessitam acompanhamento no pós-operatório com terapêutica anticoagulante. Os portadores desta síndrome podem apresentar associadamente policitemia vera ou doença mieloproliferativa. Apesar de poder ser tratada por derivações venosas, tais como porto-cava ou mesoatriais, faz-se necessário o estudo angiográfico prévio para se descartar grande comprometimento trombótico (veia cava inferior ou veias ilíacas) e análise da cronicidade do quadro clínico evidenciada pela presença de ascite, hemorragia digestiva ou encefalopatia hepática.

\section{5) Alcoolismo}

Embora os resultados iniciais do transplante hepático em alcoólatras não se mostrassem satisfatórios, trabalhos mais recentes demonstraram que os resultados em 5 anos são comparáveis ao dos pacientes com doenças colestáticas e parenquimatosas, exceto a hepatite $\mathrm{B}^{3,14,28,41}$, e que a volta ao uso do álcool foi inferior a $15 \%{ }^{18,42}$, sem que isto represente necessariamente dependência ou abuso. Atualmente procura-se discriminar dentre os alcoólatras candidatos ao transplante, aqueles que tenham deixado o uso do álcool há pelo menos 6 meses, o que seria maior garantia para a abstinência pós-transplante ${ }^{43}$.

Outros estudos revelam que $80 \%$ dos transplantados recuperam a capacidade de voltar ao trabalho ${ }^{41} \mathrm{e}$ 
ao contato social e familiar $89 \%{ }^{44}$. A recorrência ao uso do álcool costuma ser maior naqueles que haviam deixado de beber em período de tempo inferior a 6 meses antes do transplante ${ }^{16,23,42}$ e esta recorrência é também maior nos casos de hepatite alcoólica do que nos casos de cirrose ${ }^{45}$.

\section{6) Insuficiência Hepática Fulminante}

A indicação do transplante em pacientes com insuficiência hepática fulminante apresenta caráter de urgência por causa da rapidez com que se desenvolve edema cerebral grave responsável por $40 \%$ das mortes. Estes pacientes também apresentam elevado risco de desenvolver infecções bacterianas ou fúngicas que podem contra-indicar o transplante 5 . Foram elaborados critérios que permitem a indicação precoce do transplante em pacientes com alta probabilidade de morte apesar do tratamento médico intensivo, reduzindo o risco de incluir casos com possibilidade de recuperação ${ }^{(5)}$. Nestas circunstâncias a cirurgia somente está contra-indicada em situações de sepse e quando o eletroencefalograma é isoelétrico, ou no caso de drogaditos ativos.

A orientação mais adequada para os casos de insuficiência hepática fulminante, independentemente da etiologia (vírus, drogas), é enviar o paciente a um centro transplantador assim que surjam os primeiros sinais de encefalopatia hepática.

O transplante está indicado quando fatores de coagulação, como o fator V, está abaixo de $20 \%$, em associação com estado de coma ou confusão mental impor$\operatorname{tante}^{16}$. A indicação cirúrgica deve ser rápida nos pacientes com níveis de fator $\mathrm{V}<20 \%$ e com idade inferior a 30 anos e naqueles acima de 30 anos e com níveis de fator $\mathrm{V}<30 \%$, cuja mortalidade é superior a $90 \% 0^{7,16,46}$.

\section{7) Tumor de Fígado}

Estudos envolvendo o transplante hepático em carcinoma hepatocelular têm demonstrado sobrevida de $18 \%$ a $35 \%$ em 5 anos $^{1}$. Embora estes números possam indicar sucesso do ponto de vista oncológico esta sobrevida não é aceitável para o transplante hepático, onde os doadores são limitados e o transplante hepático para doença benigna oferece sobrevida de 5 anos de $65 \%$ a $75 \%$. $\mathrm{Na}$ verdade os melhores resultados são referidos para tumores menores que $5 \mathrm{~cm}$, unifocal, incidental, sem invasão vascular ou do tipo fibrolamelar.

A recidiva do carcinoma hepatocelular tem alcançado a cifra de $65 \%$ em 93 transplantes consecutivos ${ }^{1}$. Por razões ainda não totalmente esclarecidas o carcinoma hepatocelular pós-transplante tende a crescer mais rapidamente ${ }^{47}$. Nos casos de carcinoma hepatocelular pequeno em portadores de cirrose não avançada a ressecção hepática pode ser o procedimento de esco- lha e deve ser lembrado que a presença de nódulos displásicos ou de carcinomas incidentais podem estar presentes no parenquima remanescente ${ }^{48}$. Pacientes submetidos ao transplante hepático por apresentarem insuficiência hepática terminal por cirrose avançada e nos quais foram achados pequenas neoplasias apresentaram sobrevida de $88 \%$ em 5 anos $^{15,37}$.

\section{8) Indicações não usuais}

O transplante hepático resultou em cura da hemofilia A. O transplante combinado fígado-pâncreas e o multivisceral vem sendo objeto de estudos e protocolos ainda de carácter investigatório, principalmente na Universidade de Pittsburgh e de Miami ${ }^{3}$.

Com exceção da rejeição crônica, as indicações para o retransplante são as de urgência: rejeição hiperaguda, ausência de função imediata do enxerto e trombose da artéria hepática, desde que ocorram nos trinta primeiros dias após a realização do transplante de fígado.

Deste modo acredita-se que atualmente o transplante hepático, revestido de sua enorme complexidade, constitui-se na forma de tratamento dos hepatopatas terminais ${ }^{4}$. É conveniente também ressaltar que a moderna hepatologia poderá contar com outros recursos de terapêutica, ainda em fase de experimentação, como o fígado artificial e a terapêutica gênica ${ }^{49}$. Desta forma pode-se verificar através da análise dos parâmetros clínicos e bioquímicos não só a indicação do transplante de fígado, mas adequada seleção e momento oportuno para a realização deste. Procura-se oferecer melhores resultados de sobrevida e qualidade de vida após a realização da cirurgia.

\section{REFERÊNCIAS}

01. O’ Grady JG, Ploson EJ, Rolles K. Liver transplantation for malignant disease. Results in 93 consecutive patients. Ann Surg 1988;207:373-9.

02. Dickson ER, Grambsch PM, Fleming TR. Prognosis in patients with primary biliary cirrhosis: model for decision making. Hepatology 1989;10:1-7.

03. Bonsel GJ, Essink B, Klompmaker IJ. Assessment of the quality of life before and following liver transplantation: First results. Transplantation 1992;53:796-800.

04. Ringe B, Quadrenni AL. Review on liver transplantation. Amer J Gastroenterology 1994;89(8):518-26.

05. Rolando N, Harvey F, Brahm J. Prospective study of bacterial infection in acute liver failure: an analysis of fifty patients. Hepatology 1990;11:49-53.

06. Della Mata M, Gonzalez R, Fraga E. Viral recurrence after liver transplantation for acute fulminant liver disease caused by hepatitis B virus. J Hepatol 1993;18:571.

07. Belghiti J, Noun A, Sauvanet F. Transplantation for fulminant and subfulminant hepatic failure with preservation of portal and caval flow. B J Surg 1995;82:986-9.

08. Dindzans VJ, Schade RR, Van Thiel DH. Medical problems before and after transplantation. Clin Gastroenterol 1988;17:19-31. 
09. Pirsh JD, Kalayoglu MD, D' Alessandro AM. Orthotopic liver transplantation in patients 60 years of age and older. Transplantation 1991;51:431-3.

10. Keefe EB, Gettis C, Esquivel CO. Liver transplantation in patients with severe obesity. Transplantation 1994; 57:309-11.

11. Bourgeois N, Sznajer Y, Botembe N. Hepatitis C infection after liver transplantation. J Hepatol 1993;18:518.

12. Bronsther O. Prioritization and organ distribution for liver transplantation. JAMA 1994;271:140-3.

13. Christensen E, Neuberger J, Crowe J. Beneficial effect of azathioprine and predection of prognosis in primary cirrhosis: final results of an international trial. Gastroenterology 1985;89:1084-91.

14. Bird GL, O' Grady JG, Harvey FA. Liver transplantation in patients with alcoholic cirrhosis: selection criteria and rates of survival and relapse. Br Med J 1993;01:15-170.

15. Iwatzuki S, Starzl TE, Todo S. Experience in 1000 liver transplants under cyclosporine therapy: a survival report. Transpl Proc 1988;20(suppl. 1):498-504.

16. Bernuau J, Samuel D, Duran F. Criteria for emergency liver transplantation in patients with acute viral hepatitis and fator V (FV) below $50 \%$ of normal: a prospective study. Hepatology 1991;14:49A.

17. Kruger M, Tilman HL, Trantwein C. Treatment of hepatitis B virus reinfection after liver transplantation with fanciclovir. Hepatology 1995;22:449A.

18. Lucy MR, Merion MR, Henley KS. Selection for and outcome of liver transplantation in alcoholic liver disease. Gastroenterology 1992;102:1736-41.

19. Dindzans VJ, Schade RR, Gavaler JS. Liver transplantation: A primer for practicing gastroenterologists, Part I. Dig Dis Sci 1989;34(1):2-8.

20. Shaw Jr. BW. Liver transplantation. In: Moody FG, ed. Surgical Treatment of Digestive Disease. Chicago, Year Book Medical Publishers Inc., $2^{\text {nd }}$ Ed., 1990, pp. 423-54.

21. Adams PC, Ghent CN, Grant DR. Employment following liver transplantation. Hepatology 1995;21:140-4.

22. Lowell JA, Shaw BW. Selected topics in the critical care of liver transplant recipients. In: Maddrey WC, Sorrell MF eds. Transplantation of the liver $2^{\text {nd }}$ edition, pp. 571-603, Norwalk Connect, Appleton and Lange 1994.

23. Kron RAF. Liver transplantation and alcohol: who should get transplants? Hepatology 1994;20:285-325.

24. Krowka MJ. Hepatopulmonary sindrome. Current concepts in diagnostic and therapeutic considerations. Chest 1994;153:1528-37.

25. Pikul J, Sharpe M, Loundes R. Degree of preoperative mal nutrition in predictive of postoperative morbidity and mortality in liver transplant recipients. Transplantation 1993; 57:469-72.

26. Steiber AC, Gordon RD, Todo S. Liver transplantation in patients over sixty years of age. Transplantation 1991; 51:271-3.

27. Starzl TE, Van Thiel D, Tzakis AG. Orthotopic liver transplantation for alcoholic cirrhosis. JAMA 1988;260:2542-4.

28. Belle SH, Beringer KC, Detre KM. Liver transplantation in the United States: Results from the National Pitt unos liver transplant registry. In: Clinical Transplants. Terasaki P.I., Cecka J.M. Eds. Los Angeles, 1995, pp. 19-35.

29. Van Thiel DH, Schade RR, Gavaler JS. Medical Aspects of liver transplantation. Hepatology 1984; 4:793-835.

30. Otte JB. Recent developments in liver transplantation: Lessons from a 5 - year experience. J Hepatol 1991;12:386-93.

31. Starzl TE, Todo S, Tzakis A. Abdominal organ cluster transplantation for the treatment of upper abdominal malignancies. Ann Surg 1989;210:374-86.
32. Esquivel CO, Bernardos A, Demetris AJ. Liver transplantation for primary biliar cirrhosis. Gastroenterology 1988;94:1206-7.

33. Koneru B, Tzakis AG, Cassavilla A. Postoperative surgical complications. Biliary strictures post operative. Clin Gastroenterol 1988;17:71-91.

34. Shapiro JM, Smith H, Schaffner F. Serum billirubin: a prognostic factor in primary biliary cirrhosis. Gut 1979;20:137-40.

35. Farges O, Malaskagne B, Sebagh M. Primary sclerosing cholangitis: liver transplantation or biliary surgery. Surgery 1995;117:146-55.

36. Langans AN, Grazi GL, Stratta RJ. Primary sclerosing cholangitis: the emerging role for liver transplantation. Am J Gastroenterol 1991;85:1136-41.

37. HopfU, Muller B, Kuther D. Long-term follow up of postransfusion and sporadic chronic hepatitis non A non B and frequency of circulating antibodies to hepatitis $\mathrm{C}$ virus (HCV). J Hepatol 1990; 10:69-76.

38. Liaw YF, Tai DI, Chu CM. The development of cirrhosis in patients with chronic type B hepatitis: A prospective study. Hepatology 1988;8:493-6.

39. Samuel D, Muller R, Alexander G. Liver transplantation in european patients with hepatitis B surface antigen. New England J Med 1993;329:1842-7.

40. Grellier L, Mutimer D, Ahmed M. Lamivudine prophylaxis against reinfection in liver transplantation for hepatitis B cirrhosis. Lancet 1996;348:1212-5.

41. Gish RG, Lee AH, Keefe EB. Liver transplantation for alcoholic liver disease. Am J Gastroenterol 1993;88:1337-42.

42. Kumar S, Stamber RE, Gavrler JS. Orthotopic liver transplantation for alcoholic liver disease. Hepatology 1990;11:159-64

43. Osorio RW, Ascher NL, Avery M. Predicting recidivism after orthotopic liver transplantation for alcoholic liver disease. Hepatology 1994;20:105-10.

44. Berlakovich GA, Steininger R, Herbst F. Efficacy of liver transplantation for alcoholic cirrhosis with respect to recidivism and compliance. Transplantation 1994;58:560-5.

45. Bonet H, Gavaler JS, Wright HI. The effect of continued alcohol use on allograft rejection following liver transplantation for alcoholic liver disease. Gastroenterology 1993;104:1878.

46. Bismuth H, Samuel D, Gugenhein J. Emergency liver transplantation for fulminant hepatitis. Ann Int Med 1987; 107:337-41.

46. Yokoyama I, Carr B, Saitsu H. Accelerated growth rates of recurrent hepatocelular carcinoma after liver transplantation. Cancer 1991;68:2095-100.

48. Okuda K. Liver transplantation for hepatocelular carcinoma in transplantation of the liver. Maddrey WC \& Sorrell M. Feds, Appleton \& Lange, Conect, $2^{\text {nd }}$ edition, 1995, pp. 605-17.

49. Schaffner F. An overview of transplantation of the liver. In: Fabry TL, Klion FM, eds. Guide to Liver Transplantation. New York, Igaku-Shoin, 1992, pp. 1-12.

\section{Endereço para Correspondência}

Orlando de Castro e Silva Jr

Departamento de Cirurgia e Anatomia

Faculdade de Medicina de Ribeirão Preto - USP

Campus Universitário - Monte Alegre

14049-990 - Ribeirão Preto - SP

e-mail-orlandocjs@hotmail.com

Conflito de interesse: nenhum

Fonte de Financiamento: FAPESP 